\title{
旅游活动对张家界国家森林公园植物的影响
}

\author{
石 强 ${ }^{1}$ 钟林生 ${ }^{2}$ 汪晓菲 3 \\ (1 深圳职业技术学院旅游系, 深圳 518055) (2 中国科学院地理科学与资源研究所, 北京 100101)
}

(3 深圳园林集团公司, 深圳 518055)

摘 要 旅游活动对旅游地环境的影响几乎是不可避免的, 尤以对植物的影响最为显著。随着游客的大量增多及 旅游宾馆酒楼释放的废气污染物的急剧增加, 张家界国家森林公园境内的植物遭受了较为严重的污染和伤害。为 了探明旅游活动对张家界国家森林公园植物生长发育、体内化学物质成分及林木树干伤害等方面的影响，该研究 采用对比分析法, 调查分析了公园内受大气污染较为严重的接待区的几种林木叶内氟化物和 $\mathrm{SO}_{2}$ 含量及杉木 (Cunninghamia lanceolata) 生长速度的变化, 同时还对游道两边树木受游客刻伤的程度进行了调查分析。结果表明, 公园接待区杉木、柳杉 (Cryptomeria fortunei)、枫杨 (Pterocarya hupehensis) 叶片中氟化物及 $\mathrm{SO}_{2}$ 含量较对照区增大了 1.6 16 倍 杉木的直径生长量较对照区降低了 $32.3 \% \sim 57.1 \%$ 游客的乱刻乱划给金鞭溪、黄石寨等景区游道两 边的林木留下了许多伤痕, 这些伤痕主要分布在离地面 $1.2 \sim 1.6 \mathrm{~m}$ 的部位, 受伤程度与树种、树皮光滑程度、树干 与游道边缘距离及方位有关。为了保护公园内的植物, 必须改善公园内的燃料结构, 减少接待设施的数量, 并加强 对游客的环保教育。

关键词 旅游活动 植物生长 伤害 氟化物 $\mathrm{SO}_{2}$ 张家界国家森林公园

\section{EFFECTS OF RECREATION ON PLANTS IN ZHANGJIAJIE NATIONAL FOREST PARK}

\author{
SHI Qiang ${ }^{1}$ ZHONG Lin-Sheng ${ }^{2}$ and WANG Xiao-Fei ${ }^{3}$ \\ (1 Tourism Department of Shenzhen Polytechnic, Shenzhen 518055 , China) \\ (2 Institute of Geographical Sciences and Natural Resources Research, Chinese Academy of Sciences , Beijing 100101 , China) \\ (3 Shenzhen Garden Group Corporation, Shenzhen 518055 , China)
}

\begin{abstract}
The effects of recreation on the environment of tourism resorts are almost unavoidable, and these particularly affect vegetation. With the greatly increasing number of visitors and the intensive increase in air pollutants released from hotels and restaurants, the plants in Zhangjiajie National Forestr Park have been polluted and seriously damaged. In order to show the effects of recreation on the growth of plants, on the internal chemical components of plant leaves and on the damage degree of tree trunks , controlled experiments were used to investigate and analyze changes in contents of fluoride and $\mathrm{SO}_{2}$ in the leaves of several tree species, and growth rates of Cunninghamia lanceolata were compared between polluted and non-polluted areas. The degree of tree bark wounding caused by visitors along both sides of the tourism roads was also investigated. The results showed that the contents of fluoride and $\mathrm{SO}_{2}$ in the leaves of $C$. lanceolata, Cryptomeria fortunei and Pterocarya hupehensis in polluted areas increased 1.6-16 times in comparison to that of non-polluted areas ; the annual diameter increment of $C$. lanceolata growing near the reception area was reduced $32.3 \%-57.1 \%$ compared with that of the control area ; a great amount of scars on the tree trunks along the two sides of the tourism roads in Jinbianxi area and Huangshizhai area were cut by visitors, and these scars were distributed among the part of the trunks $1.2-1.6 \mathrm{~m}$ above the ground. The wound degree was mainly related to tree species, smoothing degree of the tree bark, and the distances from tree to the edge of tourism roads and the directions the trunks face. To protect the vegetation in the park, it is vital to improve the park' s fuel structure , reduce the amount of reception sites and improve the environmental education of visitors.
\end{abstract}

Key words Recreation activities, Vegetation growth, Damage, Fluoride, $\mathrm{SO}_{2}$, Zhangjiajie National Forest Park 
以植物所受的影响最为直接 (Wang \& Paul ,1997; Sun \& Walsh ,1998; Lankford，2001）,所产生的效应 也比较明显(Cole \& Trull, 1992; 朱晓帆等,1997; 刘鸡 雁等,1997;刘濡渊,1997；van Wyk et al.，2000； Jakes ,2002)。张家界国家森林公园 (以下简称公园) 面积为 $4810 \mathrm{hm}^{2}$, 境内森林茂密, 植被覆盖率高。 海拔 $800 \mathrm{~m}$ 以下地段, 分布着人工杉木林、针阔混交 林和阔叶混交林。人工杉木林主要分布在马田垭、 花溪峪、老磨湾、锣鼓塔、朝天观一带的沟谷坡地。 针阔混交林和阔叶混交林主要分布在溪谷及峰麓地 带。海拔 800 1000 m 地段主要为阔叶林带, 阳坡 及较宽的谷地以蓝果树 (Nyssa sinensis)、锥栗( Castanea henryi)、枫香 ( Liquidambar formosana)、柿 树 (Diospyros cathayensis)，灯台树 (Cornus controversa) 为 主;阴坡有多种润楠( Machilus spp.)、厚皮香( Ternstroemia gymnanthera)、大叶桜 (Prunus macrophyllas)、 稠李 (Padus grayana)、木荷 (Schima argentea) 等。海 拔 $1000 \mathrm{~m}$ 以上的山岗为团状或小片状针阔混交 林 树种主要有黄山松 ( Pinus taiwanensis)、雪松 ( Cedrus deodara)、长苞铁杉 ( Tsuga longibracteata)、乌岗 栎( Quercus phillyraeoides) 等。公园自 1982 年批准成 立以来, 游客逐年增加。2000 年以来, 公园年接待 人数都超过 100 万人次。游客的大量增加导致公园 接待区锣鼓塔的生活燃煤量也大幅度增长, 由此产 生的大气污染物也成倍增长。由于锣鼓塔位于深山 狭谷之中，且常年多静风天气，造成生活燃煤所释放 的大量有害废气长期堆积在峡谷中, 对周边的林木 产生了较为严重的危害。从 1986 年开始, 公园接待 区翠楼宾馆后西北侧的杉木林开始出现大面积黄 化, 该区的毛竹林也出现大量黄叶、落叶现象,而位 于该区的数株板栗 (Castanea mollissima) 则相继死亡 (王资荣等,1988)。在旅游开发过程中, 虽然十分注 意对林木的保护, 但仍有部分游客在游晾过程中对 游道两边林木乱刻乱划, 造成较为严重的伤害。针 对以上情况, 本研究对公园内杉木林的生长情况及 游道两边林木的受伤情况进行了调查分析, 同时还 对杉木 (Cunnighamia lanceolata)、柳杉 ( Cryptomeria fortunei)、枫杨 (Pterocarya hapehensis) 等树种叶中氟 化物及 $\mathrm{SO}_{2}$ 的含量进行了测定比较, 以评价旅游活 动对公园植物的影响, 并在此基础上提出了相应的 对策。

\section{1 研究方法}

1.1 植物叶中氟化物及 $\mathrm{SO}_{2}$ 含量的测定
1984 年及 1986 年, 湘西自治州环保局的王资荣 等 (1988) 对公园内锣鼓塔、老林场、黄石寨、金鞭溪、 水绕四门等地的杉木、柳杉及枫杨叶中氟化物的含 量进行了测定。该研究采集上述 5 个地点林分中同 样树种的叶片, 以氟离子选择性电极法测定叶中氟 化物的含量, 并与 1984 年和 1986 年的结果进行对 比, 以此来分析和评价旅游活动对公园内林木的影 响。

多年来公园内的主要大气污染物为燃煤所产生 的 $\mathrm{SO}_{2}$ (黄艺等, 1991)。因此, 测定分析公园林木叶 中 $\mathrm{SO}_{2}$ 含量的变化情况将有助于人们了解公园内大 气污染程度的变化及其对林木的影响。在以往的研 究中, 还没有对公园内林木叶中 $\mathrm{SO}_{2}$ 的含量变化进 行测定和分析。为此, 该研究分别在锣鼓塔、老林场 及黄石寨的林分中选取杉木、柳杉及枫杨叶, 用光电 比色法测定分析其 $\mathrm{SO}_{2}$ 含量, 以此来分析和评价旅 游活动对公园林木的影响。

为了使测定结果更科学, 该研究采取林木树冠 中部外缘叶片进行测定, 其中枫杨叶为当年生叶, 杉木和柳杉叶为两年生叶, 每种树叶取 3 个样, 以均 值进行比较和评价。

\section{2 杉木样地调查分析}

在接待区 (影响区) 锣鼓塔翠楼宾馆后西北侧受 污染较为严重的杉木纯林(位于 10 林班 8 小班内， 1964 年营造)内设置 4 个 $10 \mathrm{~m} \times 10 \mathrm{~m}$ 的样地, 进行 每木检尺, 量取每株林木的树高、胸径, 并记录样地 内乔木、灌木及草本的情况, 选取了 4 个形状比较一 致的标准木(平均木, 基径为 $18 \mathrm{~cm}$ 左右)伐桩(1998 年间伐桩) ,作年轮宽度测量。在树种、树龄、海拔、 坡向及立地类型等条件基本相同的马田垭 6 林班 15 小班(远离接待区, 未受到污染)中设置同样的样 地作为对照, 同样选取 4 个形状比较一致的标准木 (平均木, 基径为 $19 \mathrm{~cm}$ 左右) 伐桩, 测量其年轮宽 度。然后对样地与对照林木的树高、胸径、材积及基 径年轮宽度 (1998 年间伐桩)进行差异显著性检验， 以此来判别接待区的植物是否受到大气污染的影响 及其程度。

\section{3 林木伤害调查分析}

为了弄清公园内林木受伤及其变化情况以及影 响林木受伤的因子及其效应, 该研究在各景区选择典 型地段设置 4 个 $10 \mathrm{~m} \times 10 \mathrm{~m}$ 的样地, 记录各样地的林 木株数、植物名, 受伤林木的名称、树高、胸径、树皮粗 糙程度、距游道外沿的距离, 伤痕的数量、主要分布方 位、分布高度范围、集中分布高度范围、主体伤痕的年 
龄( 是指从伤痕产生之年开始至今的年数) 等因子。 根据调查的结果分析不同时期林木受伤的严重程度， 确定影响林木受伤的主要因子, 分析其效应。有关林 木伤害程度、树皮粗粘度、主体伤痕分布方位、伤痕年 龄等因子的统计标准作如下的划分：

伤害程度 :分为三级。一级 :为伤痕刻划笔数在 50 划以下 (一般为 1 人次刻划)，记为 1 ”;二级:为 伤痕刻划笔数在 $50 \sim 100$ 划之间 (一般为 $2 \sim 3$ 人次 刻划）记为 $2 "$;三级:为伤痕刻划笔数在 100 划以 上 (一般为 3 人次以上刻划)，记为 3 ”。树皮粗粘 度 :分为三级。一级 树皮光滑, 无剥块, 记为 1 " : 级:树皮较光滑,但有块状脱落或较浅条纹, 记为 “ 2”:三级不光滑，有较明显突起的纹路，记为 3”。 主体伤痕分布方位 :分为 3 个方向 (图 1)。斜对 :记 为 1 ”;正对记为 2 ", 背对 记为 3 ”。伤痕年龄: 分 为早、中、晚 3 个时期。早期: 伤痕年龄在 15 年以 上, 中期 :伤痕年龄在 10 年左右; 近期 :伤痕年龄在 5 年左右。

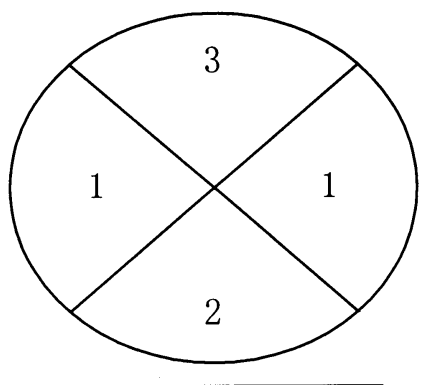

游

图 1 伤痕分布方位

Fig. 1 Distribution directions of scars

\section{2 结果分析}

\section{1 对植物叶中氟化物及 $\mathrm{SO}_{2}$ 含量的影响}

由表 1 可以看出,随着时间的推移，公园内杉 木、枫杨及柳杉 3 种林木的叶中氟化物含量都增加 了。3 种林木中以枫杨叶中氟化物的增加量最为显 著 杉木和柳杉的增幅比较接近，表明旅游开发利用 对公园植物叶中化合物含量的影响在逐渐加深, 叶 片中的大气污染物含量存在较为明显的累积现象。

对于不同地点而言,氟化物在林木叶片中的积 累程度不一样。从总体上来看, 以公园接待区锣鼓 塔的林木叶片中氟化物的积累最为明显。1984 年， 锣鼓塔的枫杨叶片中氟化物的含量仅为 $0.05 \mathrm{mg}$ $\mathrm{g}^{-1}$ 而到 1999 年, 其叶片中氟化物的含量增加到 $6.53 \mathrm{mg} \mathrm{g}{ }^{-1}, 15$ 年间增大了近 130 倍。而同期位于 水绕四门的枫杨叶中氟化物的含量只增加了近 50 倍。二者间相差 1.6 倍左右。不同地点柳杉叶中氟 化物含量的差异则更明显。1984 年, 锣鼓塔和金鞭 岩柳杉叶中氟化物含量分别为 $0.03 \mathrm{mg} \mathrm{g}^{-1}$ 和 0.01 $\mathrm{mg} \mathrm{g}^{-1}$ ，二者之间差异较小。但到 1999 年, 锣鼓塔 柳杉叶中氟化物的含量已升为 $2.21 \mathrm{mg} \mathrm{g}^{-1}$, 而金鞭 岩柳杉叶中氟化物的含量仅为 $0.13 \mathrm{mg} \mathrm{g}^{-1}$ ，二者之 间相差 16 倍。表明接待区林木叶片中大气污染物 的累积效应最大,也说明接待区的大气污染最为严 重。

公园接待区林木叶片中大气污染物含量高且增 幅大主要与接待区生活用煤的大量增加及这些煤的 含硫率太高 (达 $6 \%$ ) 有关。从表 2 我们可以看出， 公园开放之初,接待区的用煤量还较少, 1982年为

表 1 植物叶中氟化物含量 (平均值 \pm 标准差)

Table 1 Fluoride content of plant leaves $\left(\mathrm{mg} \mathrm{g}^{-1} \mathrm{DW}\right) \quad($ Means $\pm \mathrm{SD})$

\begin{tabular}{|c|c|c|c|c|c|c|c|c|c|}
\hline \multirow{2}{*}{$\begin{array}{l}\text { 测定时间 } \\
\text { Measure time }\end{array}$} & \multicolumn{3}{|c|}{$\begin{array}{c}\text { 枫 杨 } \\
\text { Pterocarya hupehensis }\end{array}$} & \multicolumn{3}{|c|}{$\begin{array}{c}\text { 柳 杉 } \\
\text { Cryptomeria fortunei }\end{array}$} & \multicolumn{3}{|c|}{$\begin{array}{c}\text { 杉 木 } \\
\text { Cunninghamia lanceolata }\end{array}$} \\
\hline & $\begin{array}{l}\text { 水绕四门 } \\
\text { Shuiraosimen }\end{array}$ & $\begin{array}{c}\text { 老林场 } \\
\text { Laolinchang }\end{array}$ & $\begin{array}{l}\text { 锣鼓塔 } \\
\text { Luoguta }\end{array}$ & $\begin{array}{l}\text { 金鞭溪 } \\
\text { Jinbianxi }\end{array}$ & $\begin{array}{c}\text { 老林场 } \\
\text { Laolinchang }\end{array}$ & $\begin{array}{l}\text { 锣鼓塔 } \\
\text { Luoguta }\end{array}$ & $\begin{array}{c}\text { 黄石寨 } \\
\text { Huangshizhai }\end{array}$ & $\begin{array}{c}\text { 水绕四门 } \\
\text { Shuiraosimen }\end{array}$ & $\begin{array}{l}\text { 锣鼓塔 } \\
\text { Luoguta }\end{array}$ \\
\hline 1984 年 & $0.03 \pm 0.01$ & $0.04 \pm 0.01$ & $0.05 \pm 0.01$ & $0.03 \pm 0.01$ & $0.08 \pm 0.02$ & $0.00 \pm 0.00$ & $0.03 \pm 0.01$ & & $0.11 \pm 0.01$ \\
\hline 1986 年 & $0.56 \pm 0.12$ & $0.85 \pm 0.15$ & $4.02 \pm 0.66$ & $0.00 \pm 0.00$ & $1.35 \pm 0.31$ & $1.05 \pm 0.24$ & $0.36 \pm 0.09$ & $0.47 \pm 0.11$ & $1.07 \pm 0.28$ \\
\hline 1999 年 & $1.86 \pm 0.35$ & $2.46 \pm 0.43$ & $6.53 \pm 0.87$ & $0.13 \pm 0.05$ & $1.86 \pm 0.46$ & $2.21 \pm 0.47$ & $0.69 \pm 0.15$ & $1.54 \pm 0.31$ & $2.63 \pm 0.53$ \\
\hline
\end{tabular}

1984 年水绕四门点未测定 The value of Shuiraosimen plot in 1984 was not determined

表 $21981 \sim 1999$ 年公园燃煤用量及污染物排放量

Table 2 Numbers of coal and air pollutants from 1981 to 1999 ( $t$ )

用煤量 Burned coal

$\mathrm{SO}_{2}$ 排放量 $\mathrm{SO}_{2}$ let

NOx 排放量 NOx let

烟尘排放量 Soot let

表中煤的平均含硫率经测定为 $6.0 \%, \mathrm{NOx}$ 为 $0.36 \%$,灰分率为 $30.7 \%$ The mean rate of sulphur contained in the coal is $6.0 \%, 0.36 \%$, and $30.7 \%$, respectively 
$500 \mathrm{t}, 1984$ 年为 $700 \mathrm{t}$ 。但到 1999 年, 接待区的用煤 量达到 $6100 \mathrm{t}$,比 1984 年增长了近 8 倍。虽然同期 公园内锅炉燃油及汽车尾气释放的大气污染物也有 相当程度的增加，但较之燃煤所释放的大气污染物 量而言，所占比例还相当小(石强等,2002)。因此, 公园接待区用煤量的大量增加是造成接待区林木叶 片内氟化物及 $\mathrm{SO}_{2}$ 含量增加的主要原因。

从图 2 可以看出, 公园不同地点植物叶片中 $\mathrm{SO}_{2}$ 含量 (干重)差异较大, 在锣鼓塔、老林场和黄石 寨 3 个采样点中, 以锣鼓塔采样点植物叶片中的 $\mathrm{SO}_{2}$ 含量最高，如在锣鼓塔采集的柳杉叶中，其 $\mathrm{SO}_{2}$ 含量达到 $16.52 \mathrm{mg} \mathrm{g}^{-1}$, 为黄石寨柳杉叶中含量的 3.21 倍。其它两个树种也同样存在这种趋势。这 说明公园接待区大气中的 $\mathrm{SO}_{2}$ 浓度大大高于其它两 个地方。

从图 2 还可以看出，不同植物叶片中的 $\mathrm{SO}_{2}$ 含 量不相同。在测定的 3 种植物中，以柳杉叶中含量 最高, 枫杨叶中含量最低。说明不同植物对 $\mathrm{SO}_{2}$ 的 吸收和累积能力不一样。这可为公园接待区树种改 造及社区绿化树种的选择提供参考。

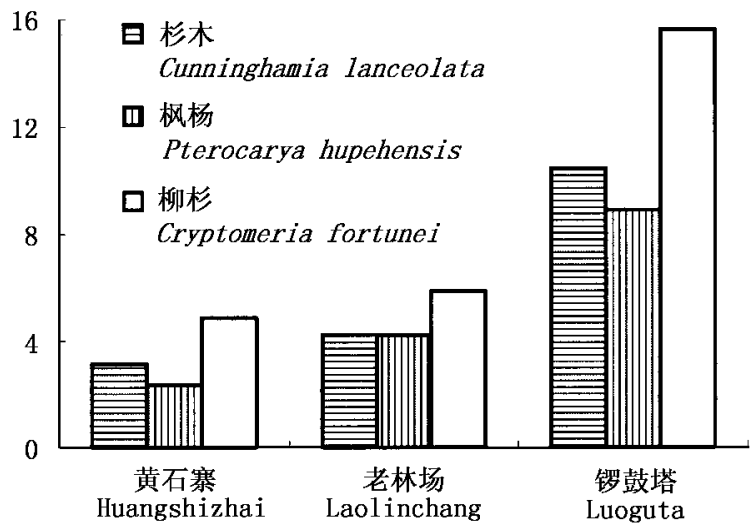

图 2 植物叶中 $\mathrm{SO}_{2}$ 含量

Fig. $2 \mathrm{SO}_{2}$ content of plant leaves

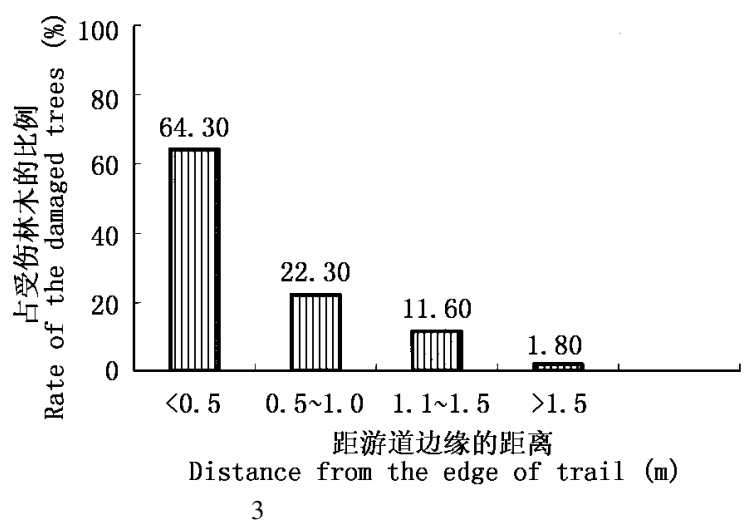

Fig. 3 Spatial distribution of damaged trees

\section{2 对杉木生长的影响}

分别对样地杉木个体的树高、胸径和材积的差 异性作显著性检验，结果(表 4)显示,受污染区杉木 成熟林个体与对照区杉木成熟林个体在树高、胸径 及材积 3 个方面都不存在明显的差异。表明公园接 待区杉木成熟林个体的树高、胸径及材积并未受到 空气污染的影响。为了探明公园的大气污染对杉木 生长是否真的没有影响，因此对杉木的连年生长情 况进行了分析。因为所调查杉木为 35 年生, 而张家 界开发旅游的历史只有 20 年, 且对林木产生影响的 大气污染主要发生在 1985 年以后(王资荣等,1988; 黄艺等, 1991)。因此, 要想真正探明旅游活动是否 对接待区杉木林构成了影响，应分析 1985 年以来杉 木的生长情况。为此，我们将 35 年的基径连年生长 量数据分成两个时段: 前 20 年(即接待区大气污染 很轻的时期)和后 15 年 (即接待区大气污染较严重 的时期），分别对 35 年、前 20 年和后 15 年的数据进 行配对检验, 看 3 种情况下的差异显著性情况, 并以 此来分析和评判旅游开发利用对公园接待区杉木林 生长的影响(表 4)。

从表 4 可以看出,在中龄林阶段以前,影响区 (锣鼓塔)和对照区 (马田垭)杉木的基径生长量都比 较接近, 但随着年龄的增长, 锣鼓塔和马田垭杉木的 基径生长量发生了明显的差异。如第四龄级的 5 年 间,锣鼓塔杉木的基径生长量只比马田垭多 $0.19 \mathrm{~cm}$ 平均每年只多长 $0.04 \mathrm{~cm}$ 。但到第五龄级 (近熟林阶段) ,锣鼓塔杉木基径的生长量比马田垭 杉木基径生长量有了明显的减小，二者间差 $0.69 \mathrm{~cm}$ 第六龄级和第七龄级也分别相差 $0.95 \mathrm{~cm}$ 和 $0.78 \mathrm{~cm}$ 。表明锣鼓塔的杉木林的生长受到了外界 的干扰。由于影响区与对照区伐班的自然条件很相 近, 说明造成生长量差异的主要原因不在于二者立 地条件的差异。

从表 4 还可以看出，影响区与对照区产生明显 差异的起始时间为 $1984 \sim 1988$ 年间, 这与公园旅游 业的发展是同步的。1984 年以前, 公园接待区只有 一处正规的接待设施, 床位 400 多个,年接待游客 4 8万人次左右。而1984 1988 年间公园共修建 各种接待设施 15 处, 新增床位 2500 多个,年接待游 客在 $22 \sim 51$ 万人次之间。大量游客的涌入导致接 待区生活用煤量的大量增加,从而形成了较为严重 的空气污染 致使公园接待区后山腰的杉木林遭受 了较为严重的污染。杉木叶片开始变黄, 并出现大 量落叶现象。叶片大量脱落及叶片叶绿素的减少致 
表 3 杉木成熟林样地标准木个体差异 $t$ 检验结果

Table $3 t$ test results of individual standard trees of mature Chinese fir forest

\begin{tabular}{|c|c|c|c|c|c|c|c|c|}
\hline $\begin{array}{l}\text { 项目 } \\
\text { Item }\end{array}$ & $\begin{array}{c}\text { 地点 } \\
\text { Site }\end{array}$ & $\begin{array}{l}\text { 均值 } \\
\text { Mean }\end{array}$ & $\begin{array}{c}\text { 标准差 } \\
\text { SD }\end{array}$ & $\begin{array}{c}\text { 均值标准误 } \\
\text { SEM }\end{array}$ & $\begin{array}{c}t \text { 值 } \\
t \text { value }\end{array}$ & $\begin{array}{c}\text { 差值标准误 } \\
\text { SED }\end{array}$ & $\begin{array}{c}\text { 显著性概率 } \\
\text { Sig. }\end{array}$ & $\begin{array}{c}\text { 差异评判 } \\
\left(p_{0.05}\right)\end{array}$ \\
\hline 胸径 & 锣鼓塔 Luoguta & 18.5 & 0.6809 & 0.0902 & \multirow{2}{*}{-1.605} & \multirow{2}{*}{0.1290} & \multirow{2}{*}{0.111} & \multirow{2}{*}{$\begin{array}{l}\text { 不显著 No } \\
\text { significance }\end{array}$} \\
\hline DBH & 马田垭 Matianya(CK) & 19.4 & 0.7261 & 0.0952 & & & & \\
\hline 树高 & 锣鼓塔 Luoguta & 15.4 & 0.4971 & 0.0658 & \multirow{2}{*}{-1.179} & \multirow{2}{*}{0.0863} & \multirow{2}{*}{0.181} & \multirow{2}{*}{$\begin{array}{l}\text { 不显著 No } \\
\text { significance }\end{array}$} \\
\hline Height of tree & 马田垭 Matianya(CK) & 15.6 & 0.4210 & 0.0558 & & & & \\
\hline 材积 & 锣鼓塔 Luoguta & 0.2138 & 0.0204 & 0.0270 & \multirow{2}{*}{-1.566} & \multirow{2}{*}{0.0039} & \multirow{2}{*}{0.081} & \multirow{2}{*}{$\begin{array}{l}\text { 不显著 No } \\
\text { significance }\end{array}$} \\
\hline Timber volume & 马田垭 Matianya(CK) & 0.2348 & 0.0310 & 0.0298 & & & & \\
\hline
\end{tabular}

表中材积采用我国农林部部颁标准《立木材积表 LY-208-77》中的杉木材积式(中华人民共和国农林部部颁标准,1978) $V=0.000058777$ $042 D^{1.969} 9831 H^{0.89646157}$ The values of timber volume were calculated by the equation $V=0.000058777042 D^{1.969} 9831 H^{0.89646157}$ of Timber Volume Table LY-208-77 issued by Chinese Agro-forestry Department (Department Standard Issued by Chinese Agro-forestry Department ,1978)

表 4 杉木标准木个体基径各龄级生长量

Table 4 Growth amount of base diameter of each age group of standard Chinese fir trees $(\mathrm{cm})$

\begin{tabular}{lccccccc}
\hline & \multicolumn{5}{c}{ 龄阶 Age group (a) } \\
\cline { 2 - 7 } & 5 & 10 & 15 & 20 & 25 & 30 \\
\hline 年际 Year range & $1964 \sim 1968$ & $1969 \sim 1973$ & $1974 \sim 1978$ & $1979 \sim 1983$ & $1984 \sim 1988$ & $1989 \sim 1993$ & $1994 \sim 1998$ \\
锣鼓塔 Luoguta (TK) & 3.27 & 8.34 & 5.73 & 2.60 & 1.44 & 0.98 \\
马田垭 Matianya (CK) & 3.04 & 7.92 & 5.64 & 2.79 & 2.13 & 1.93 & 0.59 \\
变化率 Variation rate (\%) & 7.0 & 5.1 & 1.6 & -6.7 & -32.3 & -49.6 & -57.1 \\
\hline
\end{tabular}

* 表中变化率计算式为 : $(\mathrm{TK}-\mathrm{CK}) / \mathrm{CK} \times 100 \%$ The calculating equation of variation rate is $(\mathrm{TK}-\mathrm{CK}) / \mathrm{CK} \times 100 \%$

使杉木光合作用速率降低,干物质积累降低 ,生长自 然减慢。由此可以推知 ,旅游开发利用对公园接待 区杉木的生长产生较为明显的影响。

从表 5 仍可得到上面的结论。从总体上来看, 锣鼓塔与马田垭杉木的基径连年生长量并无明显差 异, 这可能与杉木的生长习性有关。因为杉木为速 生树种, 其树高的生长主要集中在前 10 年, 而直径 的快速生长期较树高的快速生长期稍晚, 主要集中 在第五至第十五年。15 年以后, 树高和直径的生长 都开始放慢。由于调查样地为成熟林 (1964 年造 35 年生)，公园开始搞旅游开发时，其年龄为 20 年左 右, 刚好过了速生期。因此，虽然公园接待区大气污 染物对锣鼓塔后山的杉木林产生了较为严重的污 染, 但由于其生物量累积的主体部分已于污染发生 之前完成，因而 35 年间的连年生长量差异不显著。 但当将杉木的生长期按旅游开发前后分成前 20 年 和后 15 年两段时期时, 则发现前 20 年锣鼓塔和马
田垭的杉木地径连年生长量没有显著性差异, 而后 15 年则存在明显的差异。表明旅游开发利用对公 园接待区杉木的生长产生了明显的影响。

\section{3 对林木的伤害}

\subsection{1 受伤林木种类及受伤率分析}

在 6 个游览区 24 个样地进行的调查中, 共涉及 林木 79 种, 648 株。其中受到伤害的林木 29 种, 112 株, 分别占林木总种数的 $36.7 \%$ 和林木总株数的 $17.3 \%$ (表 6)。在受到伤害的 29 种林木中, 又以大 叶楠( Machilus ichangensis)、红翅械 ( Acer fabri)、利川 润楠 (Machilus lichuanensis)、大果冬青 ( Ilex macrocarpa)、灯台树、黄山松及樟 ( Cinnamomum burmanni$i$ )、水青冈 (Fagus longipetiolata) 等树皮光滑的树种所 占的比例最大,而象青榨械( Acer davidii)、南酸麥 (Choerospodias axillaris) 、栲树 ( Castanopsis fargesii)、 锥栗、杉木、青钱柳 (Cyclocarya paliurus)、柳杉、水榆 花梑 ( Sorbus alnifolia) 等树皮较粗粘的树种所占的比

表 5 杉木标准木基径连年生长量差异配对 $t$ 检验结果

Table 5 Corresponding $t$ test results of annual growth of ground diameter of standard Chinese fir trees

\begin{tabular}{|c|c|c|c|c|c|c|c|c|}
\hline $\begin{array}{c}\text { 年段 } \\
\text { Age stage }\end{array}$ & $\begin{array}{c}\text { 地点 } \\
\text { Site }\end{array}$ & $\begin{array}{l}\text { 均值 } \\
\text { Mean }\end{array}$ & $\begin{array}{c}\text { 标准差 } \\
\text { SD }\end{array}$ & $\begin{array}{c}\text { 均值标准误 } \\
\text { SEM }\end{array}$ & $\begin{array}{c}t \text { 值 } \\
t \text { value }\end{array}$ & $\begin{array}{c}\text { 标准差 } \\
\text { SD }\end{array}$ & $\begin{array}{c}\text { 双尾概率 } \\
\text { Sig. }\end{array}$ & $\begin{array}{c}\text { 差异评判 } \\
\left(p_{0.01}\right)\end{array}$ \\
\hline 35 年 & 锣鼓塔 Luoguta & 0.7186 & 0.6297 & 0.1064 & \multirow{2}{*}{-2.565} & \multirow{2}{*}{0.1298} & \multirow{2}{*}{0.015} & 不显著 No \\
\hline 35 years & 马田垭 Matanya(CK) & 0.7749 & 0.5274 & 0.0891 & & & & significance \\
\hline 前 20 年 & 锣鼓塔 Luoguta & 1.0925 & 0.0021 & 0.1346 & \multirow{2}{*}{1.609} & \multirow{2}{*}{0.0973} & \multirow{2}{*}{0.124} & 不显著 No \\
\hline Former 20 years & 马田垭 Matianya (CK) & 1.0575 & 0.5448 & 0.1218 & & & & significance \\
\hline 后 15 年 & 锣鼓塔 Luoguta & 0.2220 & 0.0850 & 0.0220 & \multirow{2}{*}{-19.584} & \multirow{2}{*}{0.0348} & \multirow{2}{*}{0.000} & 不显著 No \\
\hline Latter 15 years & 马田垭 Matianya (CK) & 0.3980 & 0.0793 & 0.0205 & & & & significance \\
\hline
\end{tabular}


表 6 公园各景区游道两边林木受伤率

Table 6 Damaged rates of trees along trails of the park

\begin{tabular}{|c|c|c|c|c|c|c|c|}
\hline $\begin{array}{l}\text { 项目 } \\
\text { Item }\end{array}$ & $\begin{array}{c}\text { 黄石寨 } \\
\text { Huangshizhai }\end{array}$ & $\begin{array}{l}\text { 金鞭溪 } \\
\text { Jinbianxi }\end{array}$ & $\begin{array}{l}\text { 腰子寨 } \\
\text { Yaozizhai }\end{array}$ & $\begin{array}{l}\text { 琵琶界 } \\
\text { Pipajie }\end{array}$ & $\begin{array}{c}\text { 沙刀沟 } \\
\text { Shadaogou }\end{array}$ & $\begin{array}{c}\text { 袁家界 } \\
\text { Yuanjiajie }\end{array}$ & $\begin{array}{l}\text { 合计 } \\
\text { Total }\end{array}$ \\
\hline $\begin{array}{l}\text { 样地林木株数 Tree number of sample sites } \\
\text { (individual plant) }\end{array}$ & 98 & 96 & 105 & 114 & 108 & 123 & 648 \\
\hline $\begin{array}{l}\text { 受伤林木株数 Number of damaged trees } \\
\text { (individual plant) }\end{array}$ & 27 & 38 & 16 & 12 & 10 & 9 & 112 \\
\hline 受伤率 Damaged rate (\%) & 27.6 & 39.6 & 15.2 & 10.5 & 9.3 & 7.3 & 17.3 \\
\hline
\end{tabular}

例就很小。

在各游览区中, 以金鞭溪游道两边林木的受伤 率最高, 接近 $40 \%$ 。黄石寨景区林木受伤率其次, 为 $27.6 \%$ 。袁家界景区因开发时间较晚, 且游道较 宽 其林木受伤率最低, 为 $9.3 \%$ (表 6)。

\subsection{2 受伤林木的空间分布}

从图 2 可以看出, 游客在游览过程中, 主要在离 游道外沿 $1 \mathrm{~m}$ 以内的林木上刻划, 尤其是距游道外 缘 $0.5 \mathrm{~m}$ 以内林木的受伤率很高。在全部样地 112 株受伤林木中, 有 97 株位于游道外缘 $1 \mathrm{~m}$ 以内, 占 $86.6 \%$ 。而其中有 72 株位于游道外缘 $0.5 \mathrm{~m}$ 以内, 占全部受伤林木的 $64.3 \%$ 。在 24 个调查样地中, 只 有两株受伤木位于距游道外缘 $1.5 \mathrm{~m}$ 以外, 仅占全 部受伤林木的 $1.8 \%$ 。因此, 受伤林木主要分布在 距游道 $1 \mathrm{~m}$ 以内的空间范围内, 距游道 $1 \mathrm{~m}$ 以外的 林木较少受到游客的伤害。

\subsection{3 伤痕特征分析}

游客在林木上刻划的主要方位在树干上与游道 正对的方向，而与游道斜对的方向较少，与游道背对 的方向则基本上未发生游客刻划事件 (表 7); 在高 度上则主要表现为, 刻划主要发生在林木树干距地 面 $0.6 \sim 1.8 \mathrm{~m}$ 的范围内, 尤其是集中分布在距地面 $1.2 \sim 1.6 \mathrm{~m}$ 的范围内。

从伤痕等级来看, 以中度伤害的比例最高 轻度 伤害的比例最低(表 7)。即受伤林木树干表皮被刻 划的笔数大多位于 $50 \sim 100$ 笔之间 (从人次上来看, 大约为两人次) ,而刻划笔数少于 50 或超过 100 的

\section{林木所占比例要小得多。}

从林木受伤的时间来看, 大部分受伤林木的主 体伤痕年龄都在 15 年左右, 其次为 10 年, 而最近 5 年则少有伤害发生。这一方面可能与游道两边可供 刻划的林木资源随着时间的推移逐渐减少有关, 另 一方面可能也与近年来游客的素质提高有关。

\subsection{4 受伤程度与林木因子相关性分析}

将受伤林木的胸径、受害方位、树皮粗粘度及受 害林木与游道外沿的距离进行相关性分析 (表 8), 发现公园各游览区游道两边受伤林木所受到的伤害 程度与其树皮粗粘度及与游道的距离两个因子显著 相关，而与林木的胸径及刻划的方位无关。即树皮 越光滑、则林木受到的伤害程度就越大，反之就越 小, 受伤林木距游道外缘越近, 则其受到伤害的程度 就越严重，反之就越轻。林木的这种受伤特点为我 们进行森林风景区开发建设及林木的保护提供了有 益的启示: 在森林风景区的建设过程中，靠近游道两 边的地方应尽量多保留那些树皮比较粗粘的树种, 这样可以避免外界的刻伤; 在老景区的树种改造过 程中，在游道两边宜多种植那些观赏性较强的粗皮 树种，而少植那些树皮比较光滑的树种。

\section{3 张家界国家森林公园植物保护对策}

张家界国家森林公园生活接待区周边林木的生 长发育已受到日益严重的大气污染的影响, 同时黄 金景区金鞭溪及黄石寨游道两边的林木受到了较为 严重的刻划伤害, 有的树木并因此而感染了病菌, 形

表 7 林木伤痕特征

Table 7 Characteristics of tree scars

\begin{tabular}{|c|c|c|c|c|c|c|c|c|c|}
\hline \multirow{2}{*}{$\begin{array}{l}\text { 项目 } \\
\text { Item }\end{array}$} & \multicolumn{3}{|c|}{$\begin{array}{c}\text { 伤痕与游道的方位关系 } \\
\text { Orientation between scar and trail }\end{array}$} & \multicolumn{3}{|c|}{$\begin{array}{c}\text { 伤痕等级分布 } \\
\text { Distribution of damaged degrees }\end{array}$} & \multicolumn{3}{|c|}{$\begin{array}{c}\text { 主体伤痕受伤时间 } \\
\text { Ages of scars }\end{array}$} \\
\hline & $\begin{array}{l}\text { 斜对 } \\
\text { Side }\end{array}$ & $\begin{array}{l}\text { 正对 } \\
\text { Face }\end{array}$ & $\begin{array}{l}\text { 背对 } \\
\text { Back }\end{array}$ & $\begin{array}{l}\text { 轻度 } \\
\text { Light }\end{array}$ & $\begin{array}{c}\text { 中度 } \\
\text { Moderate }\end{array}$ & $\begin{array}{l}\text { 严重 } \\
\text { Serious }\end{array}$ & $\begin{array}{c}5 \text { 年 } \\
5 \text { years }\end{array}$ & $\begin{array}{c}10 \text { 年 } \\
10 \text { years }\end{array}$ & $\begin{array}{l}15 \text { 年 } \\
15 \text { years }\end{array}$ \\
\hline 代号 Code & 1 & 2 & 3 & 1 & 2 & 3 & 1 & 2 & 3 \\
\hline $\begin{array}{l}\text { 数量 Number } \\
\text { (individual plant) }\end{array}$ & 19 & 93 & 0 & 26 & 54 & 32 & 10 & 42 & 56 \\
\hline 比率 Rate $(\%)$ & 17.0 & 83.0 & 0 & 23.2 & 48.2 & 28.6 & 12.5 & 37.5 & 50.0 \\
\hline
\end{tabular}


表 8 林木受伤程度与林木 (环境)因子相关性检验结果

Table 8 Correlation test results of damaged degree and environment factors

\begin{tabular}{|c|c|c|c|c|}
\hline $\begin{array}{l}\text { 项目 } \\
\text { Item }\end{array}$ & $\begin{array}{c}\text { 受伤程度与胸径 } \\
\text { Damaged degree vs DBH }\end{array}$ & $\begin{array}{c}\text { 受伤程度与方位 } \\
\text { Damaged degree vs direction }\end{array}$ & $\begin{array}{c}\text { 受伤程度与树皮粗䊁度 } \\
\text { Damaged degree vs roughness } \\
\text { degree of tree bark }\end{array}$ & $\begin{array}{c}\text { 受伤程度与距游道距离 } \\
\text { Damaged degree vs distance } \\
\text { to trail }\end{array}$ \\
\hline $\begin{array}{l}\text { 相关系数 Correlation coef- } \\
\text { ficient }(R)\end{array}$ & 0.158 & 0.100 & $-0.737^{* *}$ & $-0.562^{* *}$ \\
\hline $\begin{array}{l}\text { 双尾显著性概率 Double } \\
\text { tailed probability }\end{array}$ & 0.436 & 0.294 & 0.000 & 0.000 \\
\hline $\begin{array}{l}\text { 相关性评判结果 Result of } \\
\text { correlation judge }\end{array}$ & $\begin{array}{c}\text { 不相关 } \\
\text { No correlation }\end{array}$ & $\begin{array}{c}\text { 不相关 } \\
\text { No correlation }\end{array}$ & $\begin{array}{c}\text { 相关 } \\
\text { Correlated }\end{array}$ & $\begin{array}{c}\text { 相关 } \\
\text { Correlated }\end{array}$ \\
\hline
\end{tabular}

成了大块大块非常难看的 黑瘤”,大大降低了林木 的观赏价值。为了保护公园内的植物，一方面应采 取各种措施减少林木污染和伤害,另一方面也应增 强植物本身抗污染和伤害的能力。具体措施主要包 括改变公园境内燃料结构, 改烧高硫煤为低硫煤, 甚 至不烧煤，只烧电、烧气；迁出或关闭部分污染严重 的接待设施，或对部分接待设施安装脱硫装置，降低 有毒气体排放量;同时考虑更新营造对氟化物及 $\mathrm{SO}_{2}$ 抗性强的树种, 此外应加强对游客的宣传教育, 提高游客保护公园环境的自觉性，同时对游客的刻 划行为进行批评教育并处罚金; 在修建游道时, 应尽 量保留那些树皮较粗粘的林木, 在选择游道两边更 新树种时,也应选择那些树皮较粗糙同时具有较高 观赏价值的树种。

\section{参 考 文 献}

Cole, D. N. \& S. J. Trull. 1992. Quantifying vegetation response to recreational disturbance in the north Cascades. Northwest-Science, 66: $229 \sim 236$.

Huang, Y. (黄艺)，C. C. Wu(吴楚材) \& J. Y. Deng(邓金 阳). 1991. Assessment of environmental quality in Zhangjiajie National Forest Park. In: Research Group of Zhangjiajie National Forest Park（张家界国家森林公园课题组) ed. Study on Zhangiajie National Forest Park. Beijing: China Forestry Publishing House. (in Chinese)

Jakes, P. J. 2002. Heritage management in the U. S. forest service: a mount hood national forest case study. Society \& Natural Resources, 15:359 369.
Lankford, V. S. 2001. A comment concerning 'developing and testing a tourism impact scale'. Journal of Travel Research, 39: $315 \sim 316$.

Liu, H. Y. (刘鸿雁) \& J. H. Zhang(张金海). 1997. Effects of recreational disturbance on the Cotinus coggrgria var. cinerea forest in Xiangshan Mountain, Beijing. Acta Phytoecologica Sini$\mathrm{ca}($ 植物生态学报), 21: 191 196. (in Chinese with English abstract)

Liu, R. Y. (刘濡渊). 1997. Impacts of outdoor recreation on natural vegetation. Chinese Forestry Science Quarterly (中华林学季 刊), 29:35 58. (in Chinese with English abstract)

Shi, Q. (石强), Q. T. He (贺庆棠) \& Z.W. Wu (吴章文). 2002. Variations of air pollutant concentrations and their evaluation in Zhangjiajie National Forest Park, China. Journal of Beijing Forestry University (北京林业大学学报), 24(4):20 24. (in Chinese with English abstract)

Sun, D. \& D. Walsh. 1998. Review of studies on environmental impacts of recreation and tourism in Australia. Journal of Environmental Management, 53:323 338.

van Wyk, E., S. S. Cilliers \& G. J. Bredenkamp. 2000. Vegetation analysis of wetlands in the Klerksdorp Municipal Area, North-west Province, South Africa. South African Journal of Botany, 66: $52 \sim 62$.

Wang, C. Y. \& M. S. Paul. 1997. Environmental impacts of tourism on U.S. National Parks. Journal of Travel Research, 35:31 36 .

Wang, Z. R. (王资荣) \& X. B. Hao(郝小波). 1988. The study on the variation of environmental quality and its countermeasures in Zhangjiajie National Forest Park. China Environmental Science(中国环境科学), 8:45 48. (in Chinese with English abstract)

Zhu, X. F. (朱晓帆), H. Lu(卢红) \& Y. Jin(金燕). 1997. The study on the relationship between the activation of $\mathrm{Al}$ in soil and decline of fir forest at Mt. Emei. Environmental Science(环 境科学), 18:25 28. (in Chinese with English abstract) 